\title{
SOCIOBIOLOGÍA: UNA APROXIMACIÓN DESDE LA ESCUELA AUSTRIACA
}

\author{
ELADIO GARCÍA GARCÍA*
}

Fecha de recepción: 5 de abril de 2017.

Fecha de aceptación: 7 de octubre de 2017.

Resumen: En este trabajo se aborda el estudio de la economía desde el punto de vista de sus fundamentos básicos, tratando algunos aspectos de especial importancia, con independencia del contexto social, y con la intención clara de establecer un armazón interdisciplinar suficientemente fuerte, que utilice la analogía biológica y la metodología científica como principales herramientas de investigación, para tratar los asuntos sociales. Concretamente, se valoran dos predicados teóricos: la función empresarial (perteneciente al ámbito de la microeconomía) y la ley de la ventaja comparativa (relacionada en mayor medida con la teoría macroeconómica), y se intentan relacionar, respectivamente, con la función enzimática y la teoría simpátrica de la evolución; ambas pertenecientes en este caso al ámbito más extenso de las ciencias naturales. Para ello, se realiza una clasificación gnoseológica nueva, que pretende ordenar las distintas disciplinas dentro de unos márgenes lógicos apropiados, los cuales habrán de servirnos como nexo de unión y eje vertebrador de todo el discurso, favoreciendo su segmentación y fundamentación, y permitiendo al mismo tiempo la articulación de un estudio comparativo que tenga como finalidad cotejar algunas teorías y enunciados de la biología con aquellos correlatos sociológicos que gobiernan las relaciones humanas, el mercado libre y las disciplinas económicas. Finalmente, también se utilizan las leyes de la eficiencia dinámica y de la división del trabajo como principales constructos económicos, con la intención de demostrar el fuerte arraigo que tienen éstas teorías en la biología y la metodología más básicas, y con el objetivo último de entender la importancia que ambas adquieren en el contexto de una sociedad moderna, para impulsar la generación de bienes

* Licenciado en biología por la Universidad de León, en las especialidades de bioquímica y genética. Egresado del máster de economía de la escuela austriaca por la universidad Rey Juan Carlos de Madrid, y doctorando adscrito al departamento de economía aplicada de la misma universidad. Blog: elreplicadorliberal.com; e-mail: eladio620115588@gmail.com 
económicos, y para promover la creatividad empresarial, la especialización laboral y la expansión del conocimiento.

Palabras clave: teoría de sistemas, sociobiología, economía, función empresarial, función enzimática, ventaja comparativa, simpatría.

Clasificación JEL: A-12, A-13, B-52, B-53, D-21, D-51, E-23, F-43, L-26.

Title: Sociobiology: An approach from the Austrian School.

Abstract: This paper deals with the study of economics from the point of view of its basic foundations. It analyses some aspects of special importance, with independence of the social context, and with the clear intention of establishing a sufficiently strong interdisciplinary framework to address social issues, using the biological analogy and scientific methodology as main research tools. Specifically, two theoretical predicates are valued: the business function (belonging to the field of microeconomics) and the law of comparative advantage (more closely related to macroeconomic theory). The article tries to relate them, respectively, to the enzymatic function and the sympatric theory of evolution, both belonging in this case to the most extensive field of natural sciences. To this end, a new gnoseological classification is made, which intends to order the different disciplines within appropriate logical margins. This will serve as a union link and as the backbone of the whole discourse, favoring its segmentation and foundation, and allowing the articulation of a comparative study whose purpose is to compare some theories and statements of biology with those sociological correlates that govern human relations, the free market and economic disciplines. Finally, the laws of dynamic efficiency and of the division of labor are also used as main economic constructs, with the intention of demonstrating the strong roots of these theories in the most basic biological and methodological terms, and with the ultimate goal of understanding the importance that both acquire in the context of a modern society, in order to promote the generation of economic goods, and of business creativity, labor specialization and the expansion of knowledge.

Keywords: systems' theory, sociobiology, economics, business function, enzymatic function, comparative advantage, sympatry.

JEL Classification: A-12, A-13, B-52, B-53, D-21, D-51, E-23, F-43, L-26. 
I

OBJETIVOS BÁSICOS

\section{La función de la ciencia}

El objetivo principal de este trabajo de investigación aspira a desarrollar una fundamentación económica basada en el uso y manejo de algunas nociones y teorías pertenecientes al ámbito de la biología. La convicción que sustenta este proyecto se basa en un hecho gnoseológico que viene avalado por la propia historia. Las ciencias básicas, y los conocimientos que de ellas se derivan, siempre progresan ampliando su campo de comprensión a través de dos procesos inversos (aunque claramente complementarios): una fragmentación o especialización, y una unificación o generalización. Todas las ciencias se construyen atendiendo en mayor o menor medida a estas dos maneras principales de tratar la información. A medida que se analiza un mayor número de fenómenos, los investigadores tienden a especializarse en algún campo en particular, de los muchos que van emergiendo del proceso intelectivo. Pero, por otra parte, también se ven obligados a reparar en aquellas cuestiones de orden superior que aglutinan sus conclusiones y que se inscriben necesariamente dentro de una teoría más general (con mayor grado de universalidad), la cual, a medida que crece, está obligada a ampliar su marco de explicación para integrar un número cada vez más grande de disciplinas y contenidos.

En este sentido, la fundamentación económica que se lleva a cabo aquí utiliza algunos conceptos básicos extraídos de la biología molecular o la genética de poblaciones, con la intención firme de dirigir sus propias investigaciones en el ámbito de la sociedad, para decantar y asentar un conocimiento más general, todo lo cual supone un paso muy importante en ese camino de integración que acabamos de subrayar. No en vano, la ciencia económica tiene por objeto estudiar unos fenómenos sociales que son, en última instancia, una pequeña porción del abanico de hechos naturales que estudia la ciencia biológica. Por tanto, los principios de ésta última no pueden entrar nunca en contradicción con los postulados de aquella, e incluso, la mayoría de las veces deberían servir para explicarlos. 
Por consiguiente, el proyecto investigativo que aquí se expone responde a la más elevada de todas las ortodoxias intelectuales, la cual forma parte del carácter esencial y el objeto programático y metodológico que tiene cualquier disciplina científica, que no es otro que el de aspirar a encontrar soluciones que ayuden a elaborar un conocimiento más general, el cual con toda seguridad tendrá que acabar rebasando el borde de la materia concreta, y derramarse por las que estén en su base.

\section{La teoría general de sistemas}

La tesis que vamos a defender en este trabajo queda suficientemente legitimada gracias a todos aquellos antecedentes históricos y al estado actual que ostentan dos de los principales constructos teóricos del siglo XX: la teoría general de sistemas y la disciplina de la sociobiología. Analizaremos ahora la primera de estas teorías, y dejaremos para más adelante (en el siguiente epígrafe) el estudio de la segunda.

La teoría general de sistemas fue inicialmente propuesta y desarrollada por Ludwig von Bertalanffy, y expuesta en su libro del mismo título. En palabras del propio autor:

«...hoy en día estos problemas (y otros) los están resolviendo la teoría dinámica de los sistemas y la teoría del control. El isomorfismo entre leyes es presentado mediante ejemplos elegidos con ilustraciones intencionalmente sencillas, pero otro tanto es aplicable a casos más enrevesados, que andan lejos de ser matemáticamente triviales. Es así un hecho notable que sistemas biológicos tan diversos como el sistema nervioso central y la trama de regulación bioquímica en la célula resulten estrictamente análogos, lo cual se hace aún más significativo cuando se aprecia que esta analogía entre diferentes sistemas en diferentes niveles de organización biológica no es sino un miembro de una vasta clase de analogías» (Bertalanffy, 1976: XII).

Actualmente, la teoría general de sistemas se ha convertido, en opinión de Bertalanffy, en una disciplina madura: 
«....una disciplina reconocida, objeto de cursos universitarios, textos, compilaciones, revistas, reuniones, grupos de trabajo, centros y demás accoutrements de un campo de enseñanza e investigación universitarias» (Bertalanffy, 1976: XI).

Creemos por tanto que ya ha llegado el momento de aplicar dicha teoría al objeto de comprender también las principales cuestiones económicas que afectan al hombre, esto es, sus relaciones de intercambio, sus modos de producción, o su sistema político. De este debate deberán surgir las claves que permitan explicar la prosperidad y la capacidad de innovación de una sociedad moderna en permanente cambio.

La función principal de la teoría de sistemas es analizar las fuerzas físicas y los procesos estructurales que están en el origen de cualquier organización natural, e ir identificando las leyes generales que gobiernan esas estructuras complejas a distintos niveles, del mismo modo por ejemplo que Newton utiliza la fuerza de la gravedad para describir la caída de las manzanas o el movimiento de los planetas, entendiendo de ese modo el principio de ordenación que rige en toda la organización jerárquica.

Corresponde por tanto a la teoría de sistemas favorecer, en la medida de lo posible, la articulación de todas aquellas operaciones de transposición que permitan aplicar los conceptos tratados en distintas áreas del pensamiento, exactamente como hacen todos los científicos cuando buscan comparar y relacionar dos hechos aparentemente inconexos, al objeto de ampliar el marco de generalización de sus hipótesis de partida. Bertalanffy emplea la palabra isomorfismo para designar este tipo de operaciones. El neologismo se ajusta bastante bien a ese nuevo ámbito de estudio que son los sistemas. Pero en cualquier caso, el método que utiliza no se diferencia en lo esencial de aquellos otros que emplea la ciencia en todas sus investigaciones.

Por transposición isomórfica entendemos la comparación de dos hechos naturales al objeto de hallar un principio de ordenación subyacente, y la correspondiente relación que queda expresada en la forma de una teoría nueva más general. En nuestro caso vamos a utilizar el concepto de isomorfismo que propone Bertalanffy, suficientemente acreditado a lo largo de todos estos años, para 
parangonar algunas teorías de la biología y la economía, siendo una de tales comparaciones aquella que haremos entre la función enzimática de una célula y la función empresarial del mercado.

La transposición isomórfica es también la principal operación gnoseológica que lleva a cabo la sociobiología. No en vano, su función consiste en relacionar todos los sistemas biológicos, con el objetivo último de compararlos y asimilarlos a los sistemas sociales.

En este sentido, la propuesta principal que plantea este trabajo consiste en tomar al proceso biológico de la replicación como el isomorfismo más fundamental de todos, aquel mecanismo físico de organización que permite entender las causas básicas que están detrás del origen y evolución de toda la vida, y también de la cultura humana. Sobre todo, intentaremos aclarar las relaciones que existen entre la función enzimática de la biología y la función empresarial de la economía, y cómo estos dos procesos constituyen en último lugar dos claros ejemplos de replicación. Ya nos dice Bertalanffy que el sistema nervioso central y la trama de regulación bioquímica de la célula son sistemas estrictamente análogos. Pero en lo que nunca reparó fue en esa comparativa entre el cerebro y los genes que ofrece la posibilidad de analizar el isomorfismo más trascendental de todos: el proceso replicativo.

Una vez que entendamos y caractericemos este isomorfismo principal: la replicación, habremos conseguido identificar las causas últimas que dan origen a toda la vida y la evolución. En general, podremos hallar las claves que determinan la producción o generación de complejidad. Y lo que es más interesante seremos capaces de comprender los principales aspectos que impulsan la generación de bienes económicos y culturales cada vez más abundantes y diversos.

Posteriormente, este trabajo también se podrá extender al resto de analogías o isomorfismos naturales, aquellos que se requieren para completar la comparativa que relaciona todos los procesos de producción, económicos y biológicos. Precisamente, ese análisis completo de la naturaleza es lo que nos va a permitir abarcar el estudio de todos los mecanismos de homeostasis que aportan estabilidad a la mayoría de sistemas cibernéticos que integran la vida.

El estudio de cualquier proceso físico debe empezar por analizar su modo particular de organización. Y esto es más cierto cuanto 
más complejo es el sistema en cuestión. La complejidad de la materia empieza a incrementarse (y adquiere mayores dimensiones) con el origen de la vida. Ese origen solo tiene una causa principal: la replicación molecular. Por tanto, la teoría general de sistemas, o teoría de la complejidad, deberá empezar resolviendo un problema cardinal: el criterio de demarcación que permite conocer los mecanismos que dan origen a los seres vivos y que ponen en marcha el proceso de multiplicación genética. La solución a este problema nos tendrá que conducir a conocer también la causa general que está detrás del funcionamiento y evolución de todos los sistemas complejos, incluidas las sociedades humanas.

\section{La sociobiología a revisión}

La economía es con seguridad una de las ramas del conocimiento que más corrientes de pensamiento y más especialidades ha generado a lo largo de la historia moderna. Puede que esto se deba en parte al interés real que suscita dicha disciplina, unido también a su enorme complejidad. Para empezar, existen dos tipos de economía básicos: economía ortodoxa o neoclásica (basada en la racionalidad, el equilibrio, el keynesianismo y el empirismo científico) y economía heterodoxa, dentro de la cual podemos distinguir a su vez otras dos clases: economía especialista, que concentra su atención en el análisis de algún tema o aspecto económico muy concreto (por ejemplo Neuroeconomía, Socioeconomía, Economía Institucional), y economía generalista, que busca por el contrario una aplicación más interdisciplinar. Aquí tenemos por un lado a la Escuela austriaca, que aplica la filosofía y la metodología al estudio de la economía; por otro a la Termoeconomía, que aplica la física a los mismos asuntos; y finalmente a la Bioeconomía, que utiliza la biología. El programa de investigación de este artículo se enmarca dentro de esta última rama.

Por consiguiente, corresponde a este trabajo restringir el uso de la teoría general de sistemas a aquellas áreas de investigación que aspiren a cimentar la economía en algunos principios más esenciales relativos a la biología. Para ello, es preciso que acudamos al encuentro de una nueva disciplina científica: la sociobiología. Por 
suerte, también constatamos aquí un importante desarrollo en los últimos años, crecimiento que ha permitido a la sociobiología elevarse a la categoría de ciencia académica en solo unas décadas.

La sociobiología es la rama de la biología que aborda el estudio de las sociedades animales, y dado que el hombre es el animal que ha dado lugar a la sociedad más compleja y exitosa de todas, la sociobiología ha jugado tradicionalmente el papel de nexo de unión entre las ciencias biológicas y las ciencias humanas. Concretamente, supone un intento de aplicar los conceptos de la selección natural, la biología evolutiva o la ecología de poblaciones, al estudio de la conducta social de los homínidos actuales. En realidad, puede considerarse una forma correcta de darwinismo social.

La definición tradicional que se suele atribuir a la sociobiología ubica a esta disciplina dentro de aquella parte de la sociología que aborda el análisis de los aspectos biológicos que afectan o determinan el comportamiento social. Habitualmente, se han venido estudiando solo algunas características de la conducta humana, relacionándolas con el comportamiento general que los etólogos observan en ciertos animales gregarios. Pero en sentido amplio, podemos considerar que la sociobiología estudia cualquier aspecto biológico (función, estructura, mecanismo) que nos sirva para analizar el comportamiento humano en sociedad.

Dentro de la sociobiología podemos distinguir a su vez varias áreas diferentes. Pero quizás, la más importante sea la que aquí designamos como bioeconomía. Veamos más en detalle cómo se define y cómo se articula esta nueva rama del conocimiento.

El objetivo principal de la sociobiología es el estudio de la organización social. Y el fenómeno clave en toda organización social es la relación de interacción que establecen los distintos elementos que componen el sistema, sin la cual éste no podría existir. De igual modo, el principal motivo de estudio de la química es el enlace químico que mantiene unidas a las moléculas, sin el cual tampoco ésta ciencia tendría el menor sentido. En el caso de las sociedades humanas, ese enlace o relación fundamental queda constituido por el proceso de producción y el intercambio económico. Ese es el principal motivo de que la economía sea considerada por muchos como la reina indiscutible de las ciencias sociales (no en vano, su análisis aborda el fenómeno que determina la 
unión y agregación de todas las partes del sistema). Y también es el motivo que nos lleva a proponer aquí a la bioeconomía como su más digna representante, ya que gracias a ella podemos estudiar el proceso de la producción y el intercambio utilizando un enfoque todavía más fundamental, basado en la biología.

Uno de los principales padres fundadores y exponentes de la sociobiología es el entomólogo estadounidense Edward O. Wilson. Acudamos por tanto a las explicaciones que nos ofrece este autor, relativas a las cuestiones que aquí incluimos dentro de la bioeconomía. Wilson empieza planteando un defecto básico de las economías tradicionales:

«En la ciencia económica..., la traducción del comportamiento individual al colectivo es el problema analítico clave. Pero en estas disciplinas raramente se considera la naturaleza exacta y las fuentes del comportamiento individual... Los modelos más avanzados de micro y macroeconomía están en el buen camino. Pero los teóricos se han puesto a sí mismos impedimentos innecesarios al cerrar su teoría a la biología y a la psicología serias, que comprenden principios obtenidos de la descripción atenta, de la experimentación y del análisis estadístico. Lo han hecho, según creo, para evitar quedar enmarañados en las formidables complejidades de estas ciencias fundamentales... Las teorías económicas pretenden asimismo crear modelos que tengan una aplicación lo más general posible, con los que suelen pergeñar abstracciones tan extremas que representan poco más que ejercicios de matemática aplicada... sus modelos contienen elegantes representaciones gráficas y soluciones analíticas a problemas teóricos de equilibrios. Pero, visto a través de los principios establecidos de las ciencias del comportamiento, son simplistas y con frecuencia engañosos» (Wilson, 1999: p. 297).

La solución que Wilson propone a continuación es la siguiente:

«Instilar psicología y biología en la teoría económica y demás teorías sociales, lo que sólo puede suponer ventajas para ellas, significa desmenuzar y examinar microscópicamente los delicados conceptos de utilidad, preguntando por qué la gente se inclina en último término hacia determinadas elecciones $\mathrm{y}$, al hallarse así predispuesta, por qué y bajo qué circunstancias actúa sobre ellas. 
Más allá de esta tarea se encuentra el problema de la micro a la macroeconomía, el conjunto de procesos por los que la masa de decisiones individuales se traducen en pautas sociales» (Wilson, 1999: p. 300).

Con todo, podemos decir que Wilson acierta de pleno a la hora de plantear el problema básico, pero se equivoca en las soluciones que propone. Un poco más adelante insiste:

«En la actualidad el modelo de explicación dominante es la ya mencionada teoría de la elección racional... su concepto fundamental es que, por encima de todo, los seres humanos son racionales en sus acciones. Examinan tan bien como pueden todos los factores pertinentes, y ponderan el resultado probable de seguir cada una de las elecciones potenciales. Añaden los costes y beneficios (inversión riesgo y retorno emocional y material) antes de decidirse. La opción preferida es la que maximiza la utilidad. No es esta una imagen adecuada de cómo piensa la gente. La mente humana no es una calculadora muy veloz, y la mayoría de decisiones han de tomar se con bastante rapidez, en escenas complejas y con información incompleta. De manera que la pregunta importante en la elección racional es: ¿cuánta información es suficiente? En otras palabras: ¿en qué momento la gente deja de reflexionar y se decide?» (Wilson, 1999: p. 303).

Wilson se percata de un problema verdadero en economía: la falta de fundamentos básicos que estén apoyados en la biología. También considera por un momento la importancia que ostenta la acción individual, así como la necesidad de partir siempre de dicha acción para elaborar una teoría social más sólida. Igualmente, se da cuenta de que los equilibrios y modelos matemáticos que analizan los economistas dejan fuera de la ecuación algo tan importante como el comportamiento humano. Sin embargo, incurre en el mismo error que caracteriza a todos los positivistas y a la mayoría de científicos. Al igual que ellos, Wilson también pretende reparar estos problemas insistiendo todavía más en el análisis empírico, la psicología, y la metodología científica, con la intención clara de buscar algún patrón o modelo de intervención sostenible que le permita reconducir o enmendar las acciones humanas. Así, considera 
que el problema primordial que hay que analizar debe centrarse en resolver «cómo piensa la gente». Wilson no repara en ningún momento en la importancia intrínseca de la acción o libertad individual, aquella que resulta de dejar que sea la propia acción del individuo la que finalmente decida. Lo que pretende más bien es analizar en profundidad esas acciones, con el fulcro de la biología, para así poder determinar «cuánta información es suficiente o en qué momento se toman las decisiones».

Estas afirmaciones dejan al descubierto las verdaderas intenciones de Wilson. No le interesa lo más mínimo valorar el hecho en sí de la acción, la necesidad de que la acción emerja del propio individuo, de forma independiente, dando salida a todos sus gustos y preferencias. Lo que Wilson pretende es diseccionar y analizar esas decisiones, y utilizar ecuaciones y medidas agregadas para elaborar a posteriori unos patrones de conducta que puedan implementarse en el estudio de todas las sociedades. Wilson cae de nuevo en el error que había denunciado él mismo al inicio de sus reflexiones: «el intento por parte de los economistas de crear modelos estadísticos que tengan una aplicación lo más general posible, pergeñando abstracciones tan extremas que representan poco más que ejercicios de matemática aplicada». En realidad, Wilson pretende hacer algo muy parecido. Lo único que varía en su planteamiento es el cimiento biológico en el que dice apoyarse, pero no así la intención general de crear un modelo económico que pueda determinar qué acciones son mejores, con independencia de aquellas que toma el ciudadano de forma libre, a título personal.

Este objetivo positivista queda de manifiesto, si cabe todavía más, con el reconocimiento sincero que el autor realiza al final del capítulo que dedica a la bioeconomía:

«La magnitud de los problemas técnicos con los que se enfrentan los teóricos sociales en particular, no me importa admitirlo, intimida en extremo» (Wilson, 1999: p. 307).

Si Wilson queda intimidado por el trabajo que avizora, es sencillamente porque su visión de la economía aspira a estudiar al individuo humano sin tener en cuenta su subjetividad y sus decisiones, como si fuera un objeto científico inerte. Si Wilson hubiera entendido que 
puede renunciar a tamaña manipulación, y que los hombres ya actúan de la mejor manera posible en su ámbito particular (de forma automática), si hubiera comprendido que el orden social es esencialmente un orden espontáneo, que procede de abajo a arriba, por medio de la adición de millones de voluntades privadas, seguro que no se habría sentido tan intimidado ni se habría preocupado tanto al contemplar el enorme trabajo que le esperaba.

Murray Rothbard en El hombre, la economía y el Estado nos dice algo que puede ayudarnos a comprender estas diferencias de matices:

«La psicología contempla el problema de cómo y por qué el individuo forma escalas de valores, y para responder a esas preguntas es adecuado considerar la tendencia individual a decidirse por una alternativa... La praxeología sin embargo es una ciencia lógica basada en la existencia de la acción per se; está interesada en explicar e interpretar la acción en su sentido universal y no en un sentido particular o específico» (Rothbard, 2011: p. 309).

Una de las principales intenciones de mi estudio consiste en realizar una revisión de la sociobiología que parta de un enfoque más liberal, consciente de la necesidad que existe de emplear a la ciencia básica (la biología) para iluminar las ciencias sociales, pero consciente también de las particularidades que afectan a esas ciencias sociales, que impiden que éstas se puedan abordar con las mismas herramientas que usa a menudo el científico para desentrañar los detalles de sus investigaciones. En estos casos, estamos hablando de sistemas muy complejos, con una información inabarcable, que además están constituidos por personas, las cuales tampoco son susceptibles de ser utilizadas como cobayas. La mejor solución en estos casos es dejar que el sistema se ordene solo, esto es, que los hombres actúen libremente en pos de aquellos objetivos que creen que les van a reportar mayor felicidad. No niego la validez de los estudios estadísticos o psicológicos que buscan entender cómo realizamos nuestras elecciones y cómo podríamos manipular a los agentes para instarlos a tomar mejores decisiones. Pero dudo de la importancia real que tengan todas esas pretensiones (me parecen más importantes sus peligros). Sobre todo, es necesario comprender que muchas veces lo único que se debe hacer es permitir que el sistema se regule solo. 
Con esto solucionamos el problema de la ordenación, ya que no necesitamos conocer y controlar toda la información psicológica que atesoran las personas; también optimizamos la función del sistema, cuyos resultados siempre estarán enfocados a satisfacer los deseos y objetivos particulares de cada uno de los ciudadanos (nadie mejor que ellos sabe cuáles son esos objetivos); y finalmente favorecemos también la sensación de libertad que invade a los individuos cuando se saben dueños de sí mismos, y cuando están más seguros de alcanzar las metas que se proponen y de sentir satisfacción por las cosas que hacen. Se trataría por tanto de rescatar la noción de acción individual que maneja la escuela austriaca de economía (una de las corrientes económicas que más han insistido en esa libertad individual) para el ámbito de la sociobiología.

Ya lo dijo el profesor Jesús Huerta de Soto en su libro Socialismo, cálculo económico y función empresarial, contraviniendo la afirmación que el propio Wilson realiza más arriba:

«La acción humana es por definición siempre racional, en el sentido de que ex ante, el actor siempre busca y selecciona los medios que cree más adecuados para alcanzar los fines que considera que le merecen la pena.» (Huerta de Soto, 2010: p. 49).

Esto no quiere decir que el actor acierte siempre. Simplemente, el profesor está apelando al hecho cierto de que la mejor manera de ordenar una sociedad, la más racional de todas, es aquella que comprende la importancia de permitir que los agentes actúen de forma libre e independiente, para acomodar las necesidades de todos los ciudadanos, y lo perjudicial que resulta hacer todo lo contrario, a saber, intentar suplir esa subjetividad con mandatos que provengan de fuera, promovidos generalmente por alguna entidad ajena al individuo (por ejemplo, el Estado). Edward Wilson, en cambio, omite deliberadamente esa racionalidad implícita en la acción, y a partir de ahí elabora una teoría sociobiológica basada en una racionalidad opuesta, más acorde con el intervencionismo y las acciones colectivas de la política, dirigida a determinar cuál es la mejor manera que tienen todos los individuos de actuar, o cuándo cree él que deberían empezar a tomar decisiones. 
Pero se puede construir también una sociobiología que se base en todo lo contrario, en la libertad de acción, el mercado libre, el emprendimiento privado, el orden espontáneo, o la función empresarial. Ese es sin duda el principal objetivo al que atiende este trabajo: unir la biología con la verdadera economía, haciendo que ésta última se articule en torno a un único motor o principio de comportamiento, el elemento más fundamental que gobierna el funcionamiento natural de cualquier sociedad moderna: la acción intencional del individuo, su deseo deliberado de prosperar y sobrevivir, y por extensión, el fin último que determina la existencia y continuidad de cualquier entidad o sistema material: la acción estabilizadora de todas sus unidades. En el fondo, no hay un principio natural más importante que ese.

La economía sólo podrá triunfar, y convertirse de ese modo en una ciencia respetable, si decide seguir los mismos pasos de las demás disciplinas, y se centra como ellas en comprender el principal ingrediente del que está formada la sustancia que es su objeto de estudio (el individuo humano), como hace la física con los átomos, o la propia biología cuando analiza los genes y los alelos de un cariotipo en particular. Pero también si sabe diferenciar un átomo de una persona, entendiendo que la segunda no puede ser manipulada con las mismas herramientas que se usan para fisionar un núcleo o para reducir a la mitad una muestra de isótopos. Solo entonces la economía habrá conseguido alcanzar el estatus de ciencia real, y el lugar que se merece.

Existen ya algunas tentativas de generalizar la economía a través de su comparación con la biología. Concretamente, en España tenemos la tesis de bioeconomía del doctor Juan Carlos Martínez Coll. Pero estos intentos son bastante limitados e incompletos: solo abordan la competencia natural entre empresas. Otras veces, quienes intentan utilizar esa comparativa, suelen aportar unas soluciones harto equivocadas (es el caso de los positivistas).

En cambio, este trabajo acomete una comparativa que aspira a cubrir todo el proceso productivo, incluyendo a todos sus protagonistas (no sólo la competencia entre empresarios, como hace Martínez Coll). De ese modo, se pretende afianzar las ideas económicas en unos principios realmente fundamentales, que llegan incluso a considerar la metodología y la filosofía como una de las partes más 
esenciales del estudio, tal y como hace la escuela austriaca de economía en la mayoría de sus investigaciones.

Resumiendo, hasta ahora hemos acotado el cerco que delimita el objetivo principal de este trabajo. Para ello, hemos trazado nuestro camino a través de cuatro niveles distintos de concreción. En primer lugar, este estudio se mueve en el ámbito de las ciencias básicas, que buscan siempre la mayor generalidad posible para todas sus teorías. Dentro de la ciencia, nos hemos apoyado en la teoría general de sistemas, que analiza la realidad de los sistemas complejos a través de las diversas analogías y similitudes que encuentra en la naturaleza. A su vez, dentro de los sistemas complejos, hemos reparado en aquellas organizaciones vivas que constituyen la materia de estudio de la sociobiología y que, en último lugar, aspiran a describir el funcionamiento interno de las sociedades y los colectivos humanos. Y finalmente, hemos elegido a la bioeconomía como la rama más importante de la sociobiología, aquella que trata el fenómeno que mejor explica la unión que acontece entre los individuos que forman una comunidad.

Es por ello que la sociobiología y la bioeconomía están obligadas a afrontar un enfoque interdisciplinar completo, tienen que abordar una fundamentación biológica y metodológica suficientemente amplia, que tenga en cuenta todas aquellas analogías que están implicadas en el proceso general de la producción y la generación de bienes. En consecuencia, debemos empezar haciendo especial referencia a dos axiomas básicos de suyo incuestionables (que también utiliza la escuela austriaca): la acción y la individuación o individualidad humanas. En el siguiente epígrafe se describen las claves necesarias para llevar a cabo esta primera fundamentación.

\section{II MARCO METODOLÓGICO}

\section{La clasificación gnoseológica}

En primer lugar, corresponde a este trabajo establecer un criterio de clasificación de todas las ciencias, enumerando los distintos 
tipos de conocimiento que existen, resaltando aquellas materias que resultan más interesantes para el objetivo que se persigue, y delimitando el contexto y las circunstancias concretas que rodean las afirmaciones y demostraciones que aquí se van a realizar.

Sobre todo, nos interesa comparar la biología con la antropología (o economía), ya que de esa confrontación sale el principal refuerzo teórico que avala el modelo social de organización que aquí aspiramos a defender.

La clasificación que permita distinguir y comparar aquellas ciencias que se preocupan del estudio de la naturaleza (ciencias naturales), de aquellas otras que estudian exclusivamente al hombre (ciencias sociales) también permitirá diferenciar aquellas ramas del conocimiento que analizan la naturaleza básica de un fenómeno concreto (ciencias básicas), de aquellas otras que intentan extraer alguna aplicación práctica para el ser humano (ciencias aplicadas).

En cualquier caso, esta ordenación girará en torno a la importancia que adquiere el hombre en todo el proceso investigativo, como agente generador de conocimientos y como principal beneficiario. En consecuencia, será también la clasificación que finalmente nos abra las puertas al análisis de las habilidades técnicas y los comportamientos éticos que motivan su progreso. A tenor de esto, propondremos unas aplicaciones prácticas, e intentaremos extraer algunas conclusiones deontológicas especialmente útiles.

\section{El aparato axiomático}

Nuestro trabajo de investigación se formula a partir de dos imperativos naturales (o afirmaciones apodícticas) con una amplia raigambre en la filosofía clásica y el pensamiento general. No en vano, describen los dos atributos más esenciales de las cosas (del Ser). Escogemos por tanto estos principios porque consideramos, al igual que ya hiciera el propio Aristóteles, que no existen en el mundo otros elementos del conocimiento más generales que éstos. Para el estagirita, el análisis ontológico se descompone en dos 
axiomas principales. Por un lado está la individualidad o identidad de la cosa (el axioma de individuación):

«Es evidente pues que gracias a esta categoría, son también todas las demás, por lo tanto el Ser en su sentido primero, y no el ser algo, sino el Ser absoluto, ha de ser la sustancia [el individuo]» (Aristóteles, 2011, Libro VII: p. 208).

Y por el otro está la acción que emana de todo individuo, y que condiciona también su existencia particular (el axioma de la acción):

«De manera que, si hay un fin de todas las cosas propias de la acción, este sería el bien propio de la acción» (Aristóteles, 2012, Libro I: p. 28).

Aristóteles deja claro que estos dos principios son asiduos a la propia existencia de todas las entidades físicas, y posibilitan la misma en el plano más abstracto. Por tanto, son condiciones de posibilidad de la existencia, y constituyen requisitos fundamentales que no cabe demostrar en ningún caso.

\section{La reducción científica}

Uniendo los marcos gnoseológicos y axiomáticos que acabamos de ver más arriba, concluimos ahora que el único método de investigación válido para la ciencia es el método reduccionista. La estrategia reduccionista reúne a un conjunto de tesis ontológicas y gnoseológicas basadas en la idea de que la realidad está constituida por entidades individuales (principio de individuación) y que por tanto son estas unidades las que deben ser analizadas en primer lugar para entender cualquier fenómeno emergente que queramos explicar.

La reducción es una condición necesaria para comprender el mundo: estamos obligados a entender las causas últimas de los sistemas físicos; el funcionamiento y la influencia (o acción) de sus elementos más básicos. Cualquier búsqueda intelectual debe consistir necesariamente en un proyecto de reducción. 
Huelga decir que la generalización que plantea la sociobiología supera en ambición a la mayoría de generalizaciones que la ciencia lleva a cabo en áreas restrictivas. Pero en lo esencial no se diferencia en nada. La vocación de integración y las estrategias metodológicas son idénticas.

Por consiguiente, será también esta estrategia la que usaremos y a la que nos adscribiremos en este artículo, conscientes de la importancia de combinar la reducción científica con la integración de sistemas, al objeto de describir aquellas partes fundamentales de las estructuras (biológicas o económicas) que constituyen la raíz que está detrás del surgimiento de cualquier fenómeno complejo.

\section{III \\ MARCO TEÓRICO}

\section{Marco interdisciplinar: la relación de disciplinas}

La principal tesis gnoseológica que cimienta este trabajo tiene un neto carácter interdisciplinar: consiste en afirmar que las ciencias o materias de un orden inferior constituyen leyes y principios que deben cumplirse y aplicarse en los ordenamientos superiores, más complejos.

Comenzaremos señalando dos procesos o fenómenos económicos especialmente significativos, uno en el ámbito microscópico (el de los individuos) y otro en el plano macroscópico (el de las sociedades). Estos procesos son, respectivamente, la función empresarial y la ventaja comparativa. Ambos servirán como cabecera para introducir el resto de leyes económicas. Posteriormente intentaremos incardinar estas teorías económicas con algunos conceptos propios de la biología y la bioquímica. Concretamente, analizaremos la función enzimática y la especiación simpátrica.

En conclusión, vamos a fijar nuestra atención en algunas leyes económicas de especial relevancia, y vamos a fundamentar sus postulados sobre bases científicas más sólidas, tomando en consideración algunos fenómenos generales de la naturaleza. 


\section{Marco disciplinar: el proceso productivo}

En general, queremos abordar el estudio del principal proceso que caracteriza a un sistema físico real, aquel que viene a determinar el funcionamiento y las acciones de todos los existentes (o partes) que lo componen, su homeostasis interna o equilibrio dinámico, esto es, la organización y distribución de su materia y energía, al objeto de asegurar su posición en el espacio y su continuidad en el tiempo.

Por su parte, el análisis de la homeostasis nos deberá llevar a estudiar varias cuestiones relacionadas. Veremos que el proceso económico de producción e intercambio es la actividad homeostática por excelencia, por cuanto que es la única que incardina el suministro de materias primas con la generación de nuevos bienes. En este sentido, la producción se encarga de orquestar y dirigir el funcionamiento general de todas las estructuras que constituyen el sistema en cuestión, relacionando el origen de cualquier generación de orden con el destino efectivo de un producto determinado. Para analizar dicho proceso tomaremos como referencia al productor (el productor es el actor principal del proceso de producción) y propondremos algunos ejemplos concretos relacionados con él (en futuros estudios esperamos analizar también el resto de factores que condicionan la producción: los recursos materiales, los destinatarios de la producción, los factores ambientales, y los otros productores).

El objetivo principal que se persigue con esta fundamentación aspira a describir algunos procesos biológicos de especial relevancia, cuyo entendimiento estoy seguro que puede contribuir a comprender mejor la importancia que se asigna a otros conceptos y nociones de la economía, la cataláctica, el mercado, o el comercio de bienes y servicios (su creación, distribución y consumo).

\section{Marco comparativo: las leyes bioeconómicas}

Una vez aclarados los marcos (gnoseológicos y teóricos) que delimitan el escenario que precisa nuestra investigación, podemos pasar por fin a analizar el predicado de las leyes que protagonizan la obra. 
Estudiaremos el proceso de producción en relación con dos hechos fundamentales: la acción y la individuación, y atendiendo también a cinco elementos básicos de dicho proceso: el productor, el sustrato, el consumidor, el medio y los otros productores.

A partir de ahora nos centraremos sobre todo en la parte más científica del trabajo, pero sin desdeñar tampoco las bases metodológicas del mismo (los conceptos de acción e individuación). Para ello, abordaremos las principales leyes que conforman el núcleo teórico de la economía y la biología, a fin de poder compararlas y agruparlas en dos clases diferentes, dependiendo de si describen algún hecho relacionado con la acción productiva, o por el contrario atienden en mayor medida a la condición de individualidad que tienen que cumplir todas las entidades que participan en dicha producción (como ya hemos visto más arriba al abordar el pensamiento de Aristóteles, la acción y la individuación constituyen los dos determinantes básicos de toda la realidad).

Nuestra intención es estudiar el proceso de producción en relación con cinco elementos esenciales presentes en toda generación de bienes: el productor (el actor principal del proceso de producción), el sustrato (los recursos materiales), el consumidor, el medio, y los otros productores. No obstante, este primer artículo tiene un carácter programático y se centrará sobre todo en el análisis de aquellas cuestiones que están relacionadas solo con el productor.

\subsection{Cuadro general: estudio propedéutico}

Al objeto de llevar a cabo un estudio comparativo suficientemente amplio, vamos a utilizar todos los aspectos que acabamos de exponer para construir una tabla de dos entradas, una superior para los dos hechos fundamentales, y otra lateral para los cinco elementos principales que participan en la producción. Al cruzar esos datos (los dos determinantes con los cinco elementos), aparecen de inmediato las diez teorías más importantes de la economía, el núcleo proteico de cualquier estudio programático de la producción y el consumo de bienes y servicios. A continuación se exponen estos resultados en dos cuadros con distinto grado de detalle: 
CuAdro 1

PRIMER NIVEL DE CONCRECIÓN

PRINCIPALES TEORÍAS ECONÓMICAS

\begin{tabular}{|c|c|c|}
\hline & Acción & Individuación \\
\hline Productor & $\begin{array}{c}\text { Teoría de la eficiencia } \\
\text { dinámica }\end{array}$ & Teoría de la división del trabajo \\
\hline Sustrato & Teoría del capital & $\begin{array}{l}\text { Teoría del rendimiento } \\
\text { decreciente }\end{array}$ \\
\hline Consumidor & Teoría de costes & $\begin{array}{l}\text { Teoría de la determinación de } \\
\text { precios }\end{array}$ \\
\hline Medio & Teoría de las instituciones & Teoría monetaria \\
\hline $\begin{array}{c}\text { Otros } \\
\text { productores }\end{array}$ & Teoría de la competencia & Teoría del monopolio \\
\hline
\end{tabular}

\section{CUAdRo 2 \\ SEGUNDO NIVEL DE CONCRECIÓN \\ PRINCIPALES TEORÍAS BIOECONÓMICAS}

\begin{tabular}{|c|c|c|c|c|}
\hline $\begin{array}{c}\text { Filosofía } \\
\text { Ciencia }\end{array}$ & \multicolumn{2}{|c|}{ Acción } & \multicolumn{2}{|c|}{ Individuación } \\
\hline $\begin{array}{l}\text { Implicación } \\
\text { científica }\end{array}$ & \multicolumn{2}{|c|}{ Creatividad } & \multicolumn{2}{|c|}{ Desigualdad } \\
\hline $\begin{array}{l}\text { Jerarquía } \\
\text { científica }\end{array}$ & \multicolumn{2}{|c|}{ Microciencia } & \multicolumn{2}{|c|}{ Macrociencia } \\
\hline $\begin{array}{c}\text { Campo } \\
\text { científico }\end{array}$ & Microbiología & Microeconomía & Macrobiología & Macroeconomía \\
\hline Productor & $\begin{array}{l}\text { Análisis de la } \\
\text { acción en el } \\
\text { proceso } \\
\text { productivo y } \\
\text { en relación con } \\
\text { el productor. } \\
\text { Función } \\
\text { enzimática } \\
\text { Teoría de la } \\
\text { catálisis } \\
\text { enzimática }\end{array}$ & $\begin{array}{l}\text { Análisis de la } \\
\text { acción en el } \\
\text { proceso } \\
\text { productivo y en } \\
\text { relación con el } \\
\text { productor. } \\
\text { Función } \\
\text { empresarial } \\
\text { Teoría de la } \\
\text { eficiencia } \\
\text { dinámica }\end{array}$ & $\begin{array}{l}\text { Análisis de la } \\
\text { individuación en } \\
\text { el proceso } \\
\text { productivo y en } \\
\text { relación con el } \\
\text { productor. } \\
\text { Especialización } \\
\text { animal } \\
\text { Teoría del } \\
\text { simpatrismo }\end{array}$ & $\begin{array}{l}\text { Análisis de la } \\
\text { individuación en } \\
\text { el proceso } \\
\text { productivo y en } \\
\text { relación con el } \\
\text { productor. } \\
\text { Especialización } \\
\text { humana } \\
\text { Teoría de la } \\
\text { ventaja } \\
\text { comparativa }\end{array}$ \\
\hline
\end{tabular}




\begin{tabular}{|c|c|c|c|c|}
\hline \multirow{2}{*}{$\begin{array}{c}\text { Filosofía } \\
\text { Ciencia }\end{array}$} & \multicolumn{2}{|c|}{ Acción } & \multicolumn{2}{|c|}{ Individuación } \\
\hline & $\begin{array}{l}\text { Sustrato } \\
\text { enzimático }\end{array}$ & $\begin{array}{c}\text { Teoría del } \\
\text { ahorro y el } \\
\text { capital }\end{array}$ & Sustrato animal & $\begin{array}{l}\text { Teoría del } \\
\text { rendimiento } \\
\text { decreciente }\end{array}$ \\
\hline Consumidor & $\begin{array}{l}\text { Producto } \\
\text { enzimático }\end{array}$ & Teoría de costes & $\begin{array}{c}\text { Consumo } \\
\text { animal }\end{array}$ & $\begin{array}{c}\text { Teoría de la } \\
\text { determinación } \\
\text { de precios }\end{array}$ \\
\hline Medio & $\begin{array}{l}\text { Medio } \\
\text { enzimático }\end{array}$ & $\begin{array}{c}\text { Teoría del } \\
\text { Estado: medio } \\
\text { institucional }\end{array}$ & Medio animal & $\begin{array}{c}\text { Teoría } \\
\text { monetaria: } \\
\text { medio de } \\
\text { intercambio }\end{array}$ \\
\hline $\begin{array}{c}\text { Otros } \\
\text { productores }\end{array}$ & $\begin{array}{l}\text { Competencia } \\
\text { enzimática }\end{array}$ & $\begin{array}{l}\text { Teoría de la } \\
\text { competencia }\end{array}$ & $\begin{array}{c}\text { Relaciones } \\
\text { animales }\end{array}$ & $\begin{array}{c}\text { Teoría del } \\
\text { monopolio }\end{array}$ \\
\hline
\end{tabular}

Los conceptos que están más directamente relacionados con la acción son el concepto de creación (creatividad en el caso del hombre) y el concepto de cambio. Y las cualidades más emparentadas con la individuación (o identidad) son la desigualdad y la diferencia. La acción y la creación son conceptos íntimamente ligados (casi inseparables). No puede haber creación sin que medie algún tipo de acción o cambio emergente (alguna generación). Y lo mismo ocurre con la otra pareja de cualidades: la individualidad y la desigualdad. Curiosamente, muchas corrientes políticas y económicas denuestan abiertamente estas propiedades básicas, e intentan ordenar la sociedad en función de unos parámetros totalmente distintos, que favorecen la igualación y castigan la creatividad. Uno de nuestros objetivos aquí pretende ofrecer un marco analítico alternativo, que esté acorde con esas cualidades esenciales de la naturaleza, y que por tanto se muestre a favor de restablecer aquellas baterías de medidas que fomentan la creatividad, los cambios, la iniciativa privada, las diferencias positivas, la independencia de las personas, la libertad individual y, en definitiva, todo lo que está relacionado con la evolución y progreso de los sistemas naturales o sociales.

En todas las proposiciones y circunstancias que vamos a analizar intentaremos observar el fenómeno de la producción y la homeostasis interna de los sistemas implicados. El primer bloque 
de teorías se enmarcará dentro de la microeconomía y nos servirá para adentrarnos en el papel que juega la acción a lo largo de dicho proceso. Por su parte, las teorías que abordan la macroeconomía nos permitirán estudiar el carácter y papel de la individuación física en ese mismo proceso.

En último lugar, todos estos mecanismos biológicos y económicos vienen a confirmar una relación trascendental, la conexión íntima que existe entre los distintos niveles de organización, lo cual dice mucho a favor de la relevancia que tienen algunos fenómenos concretos. Su iteración en la naturaleza estaría poniendo de manifiesto unas causas particularmente profundas, unos motivos organizativos de necesario cumplimiento, y también una necesidad superior, de tipo político y humano. La observación de estos fenómenos resultaría fundamental para organizar correctamente la sociedad, y para contemplar un marco institucional y un régimen legal acorde con esos principios, en conformidad con algunos modelos y teorías económicas, atinente a la probidad de ciertas acciones (públicas o privadas), y a tenor de la legitimidad ética, la autoridad moral, el éxito profesional y la relativa felicidad que acaban procurando a los ciudadanos todas estas consideraciones.

En este artículo nos limitaremos a señalar dos procesos o fenómenos económicos especialmente significativos, uno en el ámbito microscópico (el de los individuos) y otro en el plano macroscópico (el de las sociedades). Estos procesos son, respectivamente, la función empresarial y la ventaja comparativa. Ambos nos servirán como cabecera para introducir el resto de leyes económicas. Posteriormente intentaremos incardinar estas teorías económicas con algunos conceptos propios de la biología y la bioquímica. Concretamente, analizaremos la función enzimática y la especiación simpátrica. Por motivos de espacio no podemos abordar ahora (en este artículo) el análisis que afecta al resto de teorías que aparecen en las tablas, el cual quedará pendiente para futuros trabajos.

\subsection{La acción productiva: función enzimática y función empresarial}

En un sentido amplio, llamamos acción productiva a todas aquellas intervenciones directas o indirectas que realiza el actor sobre 
su entorno más próximo, al objeto de procurarse algún bien económico, biológico o físico. Definimos bienes como aquellos productos materiales o circunstanciales que resultan de las modificaciones que provoca el actor en su entorno y que le procuran algún tipo de bonanza o beneficio existencial concreto. A su vez, entendemos que una de las mejores maneras de que la acción del individuo concluya con éxito es incrementando la creatividad o capacidad para inventar nuevas formas de subsistencia (que le permitan conservarse como tal).

\subsubsection{Función empresarial}

En el ámbito de la economía, la acción productiva adquiere máxima representatividad con la llamada función empresarial. Dicha función juega un papel crucial en el entramado evolutivo de todas las sociedades, y constituye un ejemplo de gran creatividad y eficiencia dinámica. La acción productiva del empresario queda englobada dentro de un hecho mucho más general, que se predica en último lugar del axioma de la acción, pero que se manifiesta en lo concreto a través de las acciones innovadoras que nutren a la industria de nuevos procesos de fabricación y relación. Como dice Jesús Huerta de Soto, la función empresarial:

«crea, descubre y transmite información sobre fines y medios, ajustando y coordinando de forma competitiva los planes contradictorios de los individuos, y haciendo posible la vida en común de todos ellos con un número y una complejidad y riqueza de matices y elementos cada vez mayores» (Huerta de Soto, 2010: p. 85).

Y es de nuevo el propio Huerta de Soto quien se encarga de matizar, en otro trabajo suyo (en su Teoría de la eficiencia dinámica), esa característica principal de la acción, su dimensión creadora. Con esto y con todo, alcanzamos a ver por fin una definición de la función empresarial mucho más detallada y clarificadora:

«Todo acto empresarial descubre, coordina y elimina desajustes sociales... el proceso empresarial de coordinación social jamás se 
detiene ni agota... consiste básicamente en crear nueva información que por fuerza ha de modificar la percepción general de objetivos y medios de todos los actores implicados. Esto, a su vez, da lugar a la aparición sin límites de nuevos desajustes que supone nuevas oportunidades de ganancia empresarial, y así sucesivamente en un proceso dinámico que nunca termina y que constantemente hace avanzar la civilización. es decir, la función empresarial no sólo hace posible la vida en sociedad, al coordinar el comportamiento desajustado de sus miembros, sino que también permite el desarrollo de la civilización al crear continuamente nuevos objetivos y conocimientos que se extienden en oleadas sucesivas por toda la sociedad; y además, y esto es muy importante, permite igualmente que este desarrollo sea tan armónico y ajustado como sea humanamente posible en cada circunstancia histórica» (Huerta de Soto, 2010: p. 78).

Huerta de Soto compara la función empresarial con una especie de Big Bang continuo que estaría permitiendo el crecimiento sin límites del conocimiento. Esta metáfora no sólo está muy bien traída, sino que además guarda una correspondencia exacta con la realidad. Propone una visión distinta de la economía, más dinámica, que mantiene una fuerte relación con los procesos que ocurren habitualmente en la naturaleza, y que por tanto también tiene un gran valor para este trabajo, para toda la economía, y para la consideración general de la propia ciencia.

Centrémonos por tanto en ver qué dice el profesor Huerta de Soto en el artículo científico que expone su teoría dinámica, donde básicamente presenta un análisis que pasa por añadir, al tradicional concepto de eficiencia, otro distinto que lo complementa y lo dinamiza:

«Esta idea de la eficiencia como la capacidad de «sacar algo de» aplicada al ámbito económico es anterior al mundo romano y puede remontarse incluso hasta la Grecia clásica en donde se utiliza por primera vez el término «economía» para referirse a la administración eficiente de la hacienda o casa familiar. Así, en el Económico, Jenofonte... se preocupa... de explicar cómo existen dos formas distintas de acrecentar la hacienda, equiparables en última instancia a dos dimensiones diferentes del concepto de eficiencia. Por un lado, la dimensión que podríamos calificar de 
«eficiencia estática» y que sería aquella que consiste en la buena gestión de los recursos disponibles (o «dados») tendente a evitar su despilfarro... Pero junto a esta dimensión del concepto de eficiencia que hemos calificado de estática, Jenofonte da entrada también a una dimensión complementaria de carácter «dinámico», que consiste en tratar de incrementar la hacienda actuando empresarialmente y comerciando con ella... Sin embargo, y a pesar de estos esperanzadores antecedentes, a partir del advenimiento de la Edad Moderna el concepto de eficiencia económica paulatinamente se estrecha y reduce, hasta llegar a referirse con carácter exclusivo a la dimensión estática, es decir, al actuar diligente tendente a evitar el despilfarro de los recursos dados» (Huerta de Soto, 2011: pp. 11-72).

En su artículo, Huerta de Soto recurre a la ciencia física, concretamente al concepto de energía, para buscar ejemplos que pongan de manifiesto los posibles errores en los que incurren los científicos e ingenieros al tratar con estos asuntos, dentro de sus respectivos campos. Su intención es comparar esta interpretación científica con la visión similar que se da entre los políticos y los economistas. Así nos dice:

«En esta evolución reduccionista, que empobrece notablemente el concepto de eficiencia con sus dos dimensiones distintas que ya había articulado Jenofonte, tiene una influencia determinante la forma en que el surgimiento y desarrollo de la física mecánica termina afectando a la evolución del pensamiento económico, especialmente a partir del siglo XIX... En este sentido la ley de la conservación de la energía, llega a adquirir un papel protagonista en el desenvolvimiento de la Física, y a nuestros efectos no debe pasar por alto su carácter esencialmente estático (la energía ni se crea ni se destruye tan sólo se transforma...). Posteriormente la segunda ley de la termodinámica enuncia que en todo proceso físico hay una parte de energía que se despilfarra, por ejemplo en forma de calor que se disipa, por lo que los sistemas físicos no serían reversibles. Ambas leyes protagonizan el gran desenvolvimiento de la Física a lo largo del siglo XIX y explican por qué la mayoría de los científicos conciben los fenómenos físicos casi exclusivamente en términos de energía. Además, la principal aplicación práctica de la ciencia física se plasma en el desarrollo de la 
Ingeniería Mecánica, construida exclusivamente en base al concepto (estático) de eficiencia energética, que se define por los ingenieros como la minimización en el despilfarro de energía. Un ejemplo muy ilustrativo es el de la máquina de vapor, que se convierte en el bien de capital más típico en la Revolución Industrial. La máquina de vapor sirve para transformar calor en movimiento y levantamiento de pesos, siendo el objetivo de todo buen ingeniero mecánico el lograr el máximo de eficiencia (estática), entendida como el máximo de movimiento con el mínimo de consumo o despilfarro de energía» (Huerta de Soto, 2011: pp. 11-72).

No obstante, aunque Huerta de Soto recurra a ejemplos extraídos de la física para demostrar la forma en la que la concepción estática habría dominado al principio (en todas las investigaciones iniciales), considero oportuno que tomemos otros ejemplos todavía mejores, obtenidos esta vez del ámbito de la biología y la evolución de la vida (que es también el ámbito en el que se enmarca este trabajo). Después de todo, la función empresarial, la competencia en materia de producción, o la generación de bienes económicos, responden a otro tipo de selección natural, una que da lugar a las mejores sociedades humanas que pueden existir. Es la biología básica, y no la física, la que utiliza algoritmos similares a la economía, y la que analiza estructuras que presentan un nivel de complejidad parecido a aquel que se da en las sociedades que construyen los hombres.

Si bien es cierto que el concepto de conservación de la energía, o la noción de pérdida de calor, pueden contribuir a acrecentar esta visión estática que puebla y nubla el entendimiento de muchos científicos y economistas, también es verdad que esas mismas concepciones implican casi siempre un cierto dinamismo interno. La energía se transforma continuamente en materia, o en otras formas de energía, y el calor se pierde siempre como consecuencia de los cambios y las transmutaciones que operan en todos los sistemas físicos. No creo que estos ejemplos sean los más apropiados para entender por qué el hombre tiene tendencia a ver el mundo como si estuviese mirando una foto fija.

Sin embargo, la biología sí ofrece en este caso una explicación mucho mejor. Es en el ámbito de la biología donde más se ha alimentado el fijismo, y también donde se ha llevado a cabo una 
verdadera revolución en contra de esta visión inmovilista de la naturaleza. Las llamadas teorías fijistas, predecesoras y contrarias a la evolución por selección natural, llevaron a los zoólogos y botánicos del pasado a interpretar el mundo de una forma completamente estática, y no fue hasta la introducción de la teoría darwiniana cuando los científicos comenzaron a tener algunas herramientas discursivas para combatir esta visión atrasada, y poder sustituirla por otra más dinámica.

Y esta realidad cronológica también se ha puesto de manifiesto en el ámbito de la biología molecular (microscópica). El hecho de que la enzimología haya propuesto en un principio una teoría que sólo atendía al mecanismo estático de la catálisis enzimática, no es más que la confirmación de esa tendencia natural del hombre a concebir el mundo como si fuese una foto fija, siendo el dinamismo y el cambio lo que resultaría en cualquier caso mucho más difícil de apreciar.

Esta torpeza inicial del hombre también vendría a demostrar la superioridad de algunos modelos económicos modernos que, esta vez sí, aspiran a introducir en sus ecuaciones unas variables dinámicas basadas en la función empresarial y la creatividad humana, en contraposición con aquellos otros más tradicionales que solo se fijan en el componente estático del problema, revelando con ello su incapacidad para profundizar en la esencia más básica de los fenómenos sociales, y poniendo de relieve las carencias y defectos que caracterizan a estas teorías estáticas frente a aquellas otras que sí han adoptado una visión más activa.

\subsubsection{Función enzimática}

El mecanismo biológico que vamos a usar aquí para analizar la acción productiva, y para poner de manifiesto su dimensión más dinámica y creativa, es la función enzimática. Dicha función describe la acción catalítica de moléculas proteicas dentro de un entorno celular homeostático. Durante este proceso las enzimas actúan como catalizadores de la conversión selectiva de un sustrato concreto en una molécula diferente que se denomina producto, acelerando de ese modo la tasa de reacción en un orden de 
millones de veces. En relación con esto, consideramos que existen algunas similitudes con el proceso de producción que se lleva a cabo en un nivel superior, en el seno de las sociedades humanas, con la actividad propia de la función empresarial. Y afirmamos que estas sinergias pueden contribuir significativamente a aumentar la comprensión de todos esos fenómenos.

Se denomina función enzimática a la actividad catalizadora que llevan a cabo las enzimas que integran un sistema biológico dado. En términos generales, la catálisis enzimática mejora la eficacia de las interacciones que acontecen entre los elementos del sistema, aumentando de ese modo la velocidad de obtención del producto. Concretamente, la catálisis enzimática disminuye la energía que se necesita para lograr un choque efectivo entre las moléculas de sustrato, lo que lleva a incrementar el número de choques que acaban generando el producto de la reacción.

Las enzimas son macromoléculas de naturaleza proteica que catalizan reacciones bioquímicas siempre y cuando éstas sean termodinámicamente posibles. Dichas enzimas son las proteínas más numerosas y específicas de la naturaleza. Se han descubierto alrededor de tres mil doscientos tipos, pero se calcula que existen muchos más. Esto pone de manifiesto el importante papel que juegan estos polímeros naturales en todos los organismos.

En la introducción que realiza Ignacio Núñez de Castro a su libro Enzimología, comenta el autor que:

«Ciertamente, el estudio de las enzimas (los agentes de la vida los llamaba el profesor Sols) nos pueden acercar, a pesar de la aspereza y sequedad del desarrollo matemático de la cinética enzimática, a entender un poco más los fenómenos vitales y, consecuentemente, a explicarnos qué es la vida, y por tanto a intentar responder algo de la gran pregunta: que es el hombre» (Núñez de Castro, 2012: p. 18).

De estas palabras del profesor Castro podemos extraer una primera definición bastante elocuente. El principal motivo que mueve a los expertos del análisis enzimático es el estudio pormenorizado de «los agentes de la vida», indudables protagonistas de las transformaciones biofísicas que acontecen en los organismos biológicos. 
Con esto, queda clara la importancia capital que desempeña esta disciplina minoritaria en el ámbito de las ciencias básicas.

Toda definición debe ofrecer una aproximación general al tema implicado, exponiendo sus cualidades esenciales de la forma más concisa posible. Así, se puede decir que la enzimología es el estudio de las enzimas: los agentes de la vida. No obstante, también es necesario que insistamos en matizar un poco esta afirmación. ¿Qué son las enzimas?, ¿cuál es su papel en el organismo?, ¿y cómo desempeñan su función? Todas estas preguntas deberán ser aclaradas a continuación.

Las enzimas son agentes que participan en el metabolismo aumentando la velocidad de las reacciones químicas. Las enzimas actúan sobre reacciones que se dan a velocidades muy bajas (termodinámicamente favorables) y lo que hacen es incrementar considerablemente esa cinética de velocidad. La forma que tiene una enzima de aumentar la velocidad de una reacción química es disminuyendo la energía libre de activación $(\Delta \mathrm{G})$. La energía de activación es la energía térmica que se debe suministrar a las moléculas reaccionantes para obtener un choque eficaz. Cuando una enzima disminuye la energía de activación de los reactantes, provoca un aumento proporcional en el número de choques efectivos. Los choques efectivos son todos aquellos encuentros que ocurren entre los reactantes o sustratos y que llevan a la formación del producto.

Existen varios mecanismos para aumentar el número de choques efectivos. La energía libre de activación es la resultante de dos componentes: el componente entálpico $(\Delta \mathrm{H})$ y el componente entrópico $(\Delta S)$, de acuerdo con la siguiente fórmula: $\Delta \mathrm{G}=\Delta \mathrm{H}-\mathrm{T} \Delta \mathrm{S}$. Así que las enzimas disponen en principio de dos opciones para disminuir $\Delta \mathrm{G}$. Pueden reducir el valor de la entalpia de activación $(\Delta \mathrm{H})$ o pueden aumentar el valor de la entropía de activación $(\Delta S)$.

Las enzimas disminuyen la entalpía de activación $(\Delta \mathrm{H})$, esto es, el calor de la reacción o cantidad de energía intercambiada con el entorno, rebajando la propia energía de estabilización del complejo activado en comparación con aquella que tendría en el seno del agua. Para ello se valen de las características químicas de su centro activo, compuesto por una bolsa apolar que envuelve a los sustratos por completo y que crea un microambiente en el que la constante dieléctrica es mucho menor que la que existiría en el medio 
acuoso. Esto hace que se eleve el número de interacciones electrostáticas entre la enzima y el sustrato, propiciando la estabilización del estado de transición activado que, consecuentemente, al resolverse, dará lugar al producto final de la reacción.

Además de rebajar la energía de activación a través de la reducción del componente entálpico, las enzimas también rebajan esa energía aumentando el valor de la variación de entropía (el valor de $\Delta S$ ) que podemos medir en el paso del complejo enzima-sustrato a complejo enzima-sustrato activado. La entropía determina el grado de desorden de un sistema en concreto. Así, por ejemplo, la entropía de una molécula depende de sus grados de libertad. Cuanto mayores son estos, mayor es también el valor de la entropía. Los grados de libertad dependen de la traslación, de la rotación o de la vibración de una molécula. Las reacciones enzimáticas transcurren en el interior de las enzimas, donde los sustratos y los reactivos del centro activo forman parte del mismo complejo. Por tanto, actúan como si sólo fuesen una molécula, y esto reduce significativamente su movimiento (sus grados de libertad), lo cual lleva a que aumente la diferencia entre ésta entropía, la de las moléculas insertas en el centro activo, y aquella que presentaban esas mismas moléculas en el seno del agua. Es decir, aumenta $\Delta S$ y disminuye $\Delta G$ (para que se cumpla la fórmula que hemos enunciado más arriba).

Un tercer mecanismo que reduce la energía de activación del complejo enzima-sustrato, y que aumenta el efecto multiplicador de la velocidad de reacción, viene determinado por la orientación que adquieren los orbitales de los reactantes al unirse a la proteína catalítica, lo cual permite que se favorezca la aproximación, el encuentro y el tiempo de residencia de los mismos en el interior del complejo enzimático, y, consecuentemente, también la creación de su forma activada.

Finalmente, en los últimos años se han descubierto otros mecanismos de activación más sutiles, que estarían favoreciendo igualmente el aumento de la velocidad de reacción, pero que responderían a una visión menos clásica del mundo, más relacionada con la física cuántica o el conocido efecto túnel. En su libro de enzimología, Ignacio Núñez de Castro resume perfectamente este enfoque novedoso: 
«No podemos ocultar que... después de cincuenta años de la aplicación por Pauling de la teoría del estado de transición a la catálisis enzimática, el paradigma se está cuestionando y aparece el efecto túnel de pequeñas partículas a través de la barrera energética de la coordenada de reacción, como teoría alternativa de explicación de la catálisis enzimática... La consideración de las enzimas como estructuras estáticas, no teniendo en cuenta su elastoplasticidad intrínseca y sus continuos pequeños cambios conformacionales... se adapta muy bien a la teoría del estado de transición. La enzima es considerada como complementaria al estado activado del sustrato y, partiendo de esta hipótesis, se han construido la mayor parte de las teorías para explicar las interacciones electrostáticas, la formación de determinados enlaces o la acomodación de las moléculas al sitio activo... Sin embargo, la consideración dinámica de la proteína como una macromolécula sometida a continuos cambios conformacionales sugiere más bien que la barrera energética es fluctuante, y algunos efectos catalíticos pueden explicarse por el efecto túnel a través de la barrera energética» (Núñez de Castro, 2012: p. 94).

En algunos casos partículas muy pequeñas pueden penetrar una barrera energética mayor que su propia energía cinética, eludiendo de ese modo las leyes de la mecánica clásica, y respondiendo mejor al carácter cuántico que detentan las ondas-corpúsculo que ya describió Einstein en sus ecuaciones de principios del siglo XX.

Existen varias demostraciones empíricas que prueban la validez de esta nueva interpretación de la eficiencia para el caso de algunas enzimas. La vibración molecular y el carácter cuántico de la materia estarían jugando también a favor de la disminución del valor de la energía de activación, lo que a su vez aumentaría todavía más la velocidad de la reacción.

Costó mucho que los investigadores comprendieran esta nueva faceta (más dinámica) de las enzimas. Hasta hace bien poco solo tenían una imagen cuadriculada de las mismas, un modelo de llave y cerradura en el que se representaba a los reactantes acoplándose a la perfección dentro del centro activo del catalizador, y a éste con la forma exacta para que se diera dicho ensamblaje. Es muy significativo que esto mismo haya pasado también en el campo de la economía y la política, donde la mayoría de investigadores defienden, 
todavía hoy, una visión cuadriculada de la realidad. Así, a muchos les cuesta comprender los aspectos más dinámicos del proceso productivo, y suelen apoyar medidas que tienden a fomentar la distribución de los recursos dados, sin apenas reparar en la producción de los mismos, como si la creatividad y el dinamismo no existiesen en absoluto, o como si todo lo que tuviéramos que hacer fuera sentarnos a pensar cómo vamos a repartir las ganancias y plusvalías que al parecer caen del cielo.

Pero, hete aquí que el progreso se basa sobre todo en el descubrimiento y la innovación, en la creatividad del hombre, y en la función del empresario que genera nueva información. Si la vida fuese un juego de suma cero en el que todo estuviera dado, solo sería necesario pensar cómo vamos a distribuir los bienes, no habría nada que crear, y no existiría la evolución. Pero la realidad es muy distinta, y las evidencias del progreso y el dinamismo se manifiestan a todos los niveles. Dichas certitudes también se pueden comprobar, salvando las distancias, cuando analizamos la capacidad que tienen algunas enzimas para producir aleatoriamente nuevas conformaciones espaciales, hasta dar con aquellas que permiten el cambio adecuado y la fabricación del producto (o bien).

La teoría de la eficiencia dinámica que desarrolla el profesor Jesús Huerta de Soto propone un concepto de eficiencia que, ahora sabemos, tiene reflejo también en el campo de la biología molecular, pudiendo ser aplicado por tanto a todos los niveles (sociales o naturales). En relación con este asunto, el español Ignacio Núñez de Castro, a la sazón profesor emérito de enzimología, ya se expresaba hace algunos años en los mismos términos (Núñez de Castro, 2012: p. 94), dividiendo la eficiencia de las enzimas en dos tipos distintos: estática y dinámica, y reivindicando la segunda como la más precisa de las dos, de forma bastante similar a como la presenta el propio Huerta de Soto.

A fin de cuentas, la creación es la principal característica que define a un actor o un productor; su leitmotiv. Podemos actuar para modificar el entorno en nuestro propio beneficio, o podemos ser todavía más creativos y cambiar nosotros mismos para propiciar a su vez un cambio del entorno totalmente novedoso. Esto último es lo que ocurre cada vez que aparece una nueva mutación 
adaptativa en el acervo genético de una especie, o cada vez que surge una nueva idea en la cabeza de algún empresario, o cada vez que se genera una nueva conformación en el seno de una enzima. $Y$ es de vital importancia que entendamos esto, pues todos los actos que participan en el progreso de la vida tienen siempre algún componente creativo. Sobre todo, debemos atender a esa visión dinámica de la economía y del mundo en general, y soltar el lastre que supone seguir abrazando una concepción fijista mucho más atrasada y empobrecedora.

En definitiva, lo que tenemos que hacer aquí es ir todavía un paso más allá, y analizar las claves básicas que están detrás de la evolución de toda la complejidad que observamos en la naturaleza. Pero para ello, no podemos quedarnos en la comparación que acabamos de hacer (la que relaciona la función catalítica de las proteínas con la función empresarial del mercado). Tenemos que aludir a un caso especial de catálisis: la autocatálisis. A fin de cuentas, la acción habitual de una enzima siempre tiene una naturaleza operativa. Los catalizadores no suelen evolucionar. Los cambios conformacionales que adopta la proteína, ya sean éstos clásicos o cuánticos, siempre son iteraciones repetitivas de un mismo proceso, que busca una y otra vez idéntico objetivo: la transformación de un sustrato en producto. Sin embargo, los cambios a los que se refiere Huerta de Soto en su teoría de la eficiencia dinámica, apelan a la función creativa del empresario, y son cambios de tipo evolutivo, que disponen la estructura de un modo completamente distinto. En este sentido, el cerebro sí es una máquina evolutiva. Las ideas relacionales que surgen en la mente de aquellos empresarios que encuentran una nueva oportunidad de negocio se corresponden con una estructura sináptica que, hasta ese momento, no se había dado en la cabeza de los susodichos, y que acabará fijándose en sus memorias y transmitiéndose a las siguientes generaciones como lo hace cualquier información genética.

Por lo tanto, propongo que la analogía correcta que deberíamos contemplar consiste en comparar la función empresarial, no con la función enzimática típica (proteica) que interviene en el metabolismo general, sino con la función de unas pequeñas moléculas llamadas ribozimas, que son los antecesores más antiguos de los genes. Las ribozimas son estructuras moleculares muy sencillas 
que catalizan su propia replicación de manera autónoma. Gracias a esta función enzimática primigenia es por lo que surge la vida y se pone en marcha el proceso de la evolución (hipótesis del mundo de ARN). Y ahí radica también la enorme importancia que adquiere la función empresarial en el panorama social, algo que viene reivindicando la Escuela austriaca en un gran número de trabajos.

La función empresarial juega un papel indiscutible como principal fuente de descubrimiento y nuevas oportunidades, y es el equivalente cultural de esa otra función enzimática que algún día puso en marcha el proceso evolutivo y dio lugar al surgimiento inicial de la complejidad y desarrollo de las estructuras biológicas (y que hoy sigue actuando para propiciar la replicación molecular en el seno de las células). Así, los cambios conformacionales que sufren las ribozimas (o los genes actuales) y los cambios de relación que asisten al cerebro humano durante el proceso de descubrimiento empresarial, constituyen dos mecanismos hermanos, y son la base de la evolución o la eficiencia dinámica evolutiva, uno en el ámbito de las adaptaciones biológicas y el otro en el ámbito de la evolución cultural. No en vano, Richard Dawkins utilizó el nombre de memes para designar a esos nuevos replicadores cerebrales. En este sentido, acabamos de describir el principal isomorfismo que debería tener en cuenta la teoría general de sistemas: el proceso de la replicación (uno de los propósitos programáticos de este artículo).

La capacidad creativa del empresario (o el productor) responde al mismo mecanismo evolutivo de cambio que opera a nivel molecular, pero representado esta vez en los replicadores meméticos del cerebro. El cambio de un replicador tiene siempre la posibilidad de conservarse (de replicarse) y supone por esto una oportunidad para probar una nueva conformación estructural, que acaso sea más adaptativa que la anterior. Esa es la base de cualquier evolución natural, y también de la evolución cultural. La teoría de la eficiencia dinámica del profesor Huerta de Soto está apelando al mismo proceso que ha venido permitiendo y generando la evolución de toda la vida. No es otra cosa que esa misma evolución en el ámbito de la cultura y la sociedad. En su caso, son los memes del empresario los que se someten a reproducción diferencial, compitiendo entre sí para favorecer al consumidor, cambiando la 
conformación relacional del cerebro, experimentando nuevas posiciones y alcanzando nuevas soluciones y estabilizaciones adaptativas (o económicas). Y no es sino la misma evolución elevada a la enésima potencia, pues de todos es sabido que los replicadores meméticos sufren variaciones adaptativas que acontecen todos los días (no solo con el paso de una generación a otra, como ocurre con la evolución darwiniana), se reproducen continuamente con el intercambio de ideas y el lenguaje, y se dirigen a un fin intencional concreto (no son tan azarosos como las mutaciones de los genes), que preludia un éxito mucho más rápido.

Por todo, la evolución cultural sufre una aceleración nunca antes conocida en la historia de la vida (en la que el empresario es uno de sus principales protagonistas), y la eficiencia dinámica se dispara, en este caso, a unas tasas imposibles de alcanzar en el mundo de los genes. Todo ello hace que la teoría de la eficiencia dinámica y la función empresarial (que analiza el profesor Huerta de Soto en algunos de sus trabajos) adquiera tamaña importancia, reclame una atención prioritaria por parte de todos los economistas, y se convierta en la única responsable de aquellas explicaciones que permiten comprender los verdaderos resortes que están detrás del progreso de los sistemas complejos y, en definitiva, del bienestar general que asiste a los individuos que componen las sociedades humanas más desarrolladas.

\subsection{La individuación productiva: simpatrismo y ventaja comparativa}

Llamamos individuación productiva al proceso de diversificación y especialización que acontece en el seno de un sistema natural de producción, y que lleva a los individuos que componen dicho sistema a centrarse en una actividad concreta o restringirse a un área de trabajo determinada. El proceso de especialización propicia las desigualdades de los distintos componentes del conjunto, acentuando sus diferencias y remarcando sus características particulares. Dicho proceso constituye además una implicación lógica del principio axiomático de la individuación. La mera existencia de entidades individuales hace que esa individualidad (su insistencia o su amplificación) constituya por sí misma un valor 
ciertamente importante. Todas las cosas son entes individuales y actúan como tales; todas ellas funcionan por y para atender esa característica elemental. Por tanto, cualquier proceso que vaya en la línea de favorecer ésta individualidad primaria tendrá garantizado un plus de efectividad. Por consiguiente, no resulta muy difícil entender por qué la desigualdad constituye, junto con la creatividad que asociamos más arriba a la acción, el punto arquimédico sobre el que debe pivotar cualquier teoría que quiera comprender el funcionamiento interno y las causas de la evolución de un sistema o un conjunto social.

La ley económica más importante que vamos a estudiar aquí es la ley de la ventaja comparativa. En este caso lo que se analiza es el fenómeno de la diversificación, el intercambio de bienes y el comercio internacional, y se concluye con una defensa teórica de la división del trabajo y la especialización laboral. Y, del mismo modo que la principal teoría de la acción productiva (la teoría de la eficiencia dinámica) presentaba, como vimos más arriba, una clara correspondencia con el mundo de la biología, concretamente con la dimensión dinámica de la catálisis enzimática, ahora también podremos establecer otra equivalencia similar. Compararemos la ventaja comparativa con la teoría evolutiva de la especiación simpátrica, y seremos capaces de extraer de nuevo algunas claves importantes que permitan elaborar una analogía parecida y una fundamentación mayor.

No hay duda de que existe una fuerte relación entre la eficiencia de un sistema cualquiera y su grado de especialización, relación que se puede rastrear incluso más allá de la economía, si acudimos al estudio de las ciencias naturales. Jonathan Weiner, reconocido escritor especializado en temas científicos, nos ofrece un ejemplo muy significativo:

«Lo esencial es la eficiencia, o lo que los economistas de la época de Darwin ya denominaban la división del trabajo... La ventaja de la divergencia es, de hecho, la misma que la división fisiológica del trabajo en los órganos de un mismo individuo, escribe Darwin en el Origen. No es de extrañar que Darwin recuerde el resto de su vida el lugar exacto del camino donde concibió esa visión» (Weiner, 2002: p. 232). 
A continuación repasaremos y abundaremos en estas ideas que esboza Weiner, al objeto de entender mejor cómo se vertebra todo el conocimiento en torno a estos conceptos fundamentales relativos a la individualidad o identidad de las cosas.

\subsubsection{La ventaja comparativa}

La teoría de la ventaja comparativa fue inicialmente propuesta para demostrar que los países tienden a especializarse en la producción y exportación de aquellos bienes que fabrican con un coste relativamente más bajo respecto al resto del mundo, y que de igual manera tenderán a importar los bienes en los que son más ineficaces y que por tanto producen con unos costes comparativamente más altos que el resto de naciones.

Esta teoría fue desarrollada por David Ricardo a principios del siglo XIX, y su postulado básico dice que, aunque un país no tenga ventaja absoluta en la producción de ningún bien, es decir, aunque fabrique todos sus productos de forma más cara que en el resto del mundo, le convendrá especializarse en aquellas mercancías para las que su ventaja sea comparativamente mayor o su desventaja comparativamente menor.

No obstante, aunque inicialmente se aplicó a la economía, la ley de la ventaja comparativa se sustenta en unos principios más generales, que pueden aplicarse casi a cualquier cosa. No en vano, la tendencia a la especialización es una propensión fundamental que dirige la evolución de cualquier cambio natural. Las especies biológicas surgen gracias a una especialización que las dota de una característica corporal que las capacita para adaptarse a un entorno determinado. Y cuanto más se especializan, más eficacia alcanzan en el desempeño de sus funciones vitales. Obviamente, la especialización también puede traer consecuencias negativas, por la excesiva dependencia que se crea hacia determinadas circunstancias, lo cual puede llevar a la extinción inmediata del especialista, en el caso de que falte esa coyuntura. Pero ese es un problema derivado. Lo que es innegable es que toda especie surge para acomodarse a unas circunstancias particulares, y eso es sin duda lo que significa la especialización. Adaptación y especialización son, bajo este punto de 
vista, dos efectos sinónimos. No es extraño por tanto que Ricardo decidiese utilizar la ley de la ventaja comparativa en el ámbito más general de todos: el comercio internacional, para resaltar las particularidades que condicionan y permiten cualquier intercambio de bienes. No obstante, lo que debe quedar claro es que la norma en cuestión se cumple en todos los órdenes de la naturaleza, no solo cuando analizamos una sociedad, sino también cuando estudiamos la evolución de la vida y la adaptación biológica de cualquier especie.

\subsubsection{La especiación simpátrica}

El mecanismo biológico que vamos a usar aquí para ilustrar la importancia de la individuación y el alcance de la desigualdad es el que acontece con la especiación simpátrica. Este mecanismo consiste en la formación de una nueva especie sin que se establezca una barrera geográfica entre poblaciones. Por tanto, dicho proceso estaría poniendo de manifiesto la tendencia espontánea que existe en la naturaleza a la diferenciación y diversificación de cualquier especie animal, y nos estaría hablando también del importante papel que juega en la sociedad ese mismo fenómeno, esto es, la especialización laboral y la ventaja comparativa.

Darwin entendió muy pronto, cuando recorría como naturalista los islotes de las Galápagos, que el aislamiento de las poblaciones que habitaban esa región del mundo había provocado una divergencia natural que enseguida se tradujo en un número de especies distintas en cada una de las islas. Es fácil comprender que, cuando existen barreras físicas que impiden la mezcla genética, las poblaciones aisladas acaban presentando rasgos fenotípicos ligeramente distintos que, con el paso del tiempo, van acrecentando sus diferencias. Pero esto no resolvía un problema que traía de cabeza a Darwin. Dentro de su propia isla, las diferentes especies de pinzones no se encuentran aisladas las unas de las otras, y sin embargo se ha visto que siguen sufriendo un proceso de especiación semejante al que ocurre entre pinzones que sí están separados por el agua que baña las distintas costas. ¿Qué mecanismo de la naturaleza podría haber 
obrado para forzar a las poblaciones a diferenciarse todavía más, aún en ausencia de barreras físicas?

En su delicioso libro, El Pico del Pinzón, Jonathan Weiner recoge un episodio autobiográfico de la vida de Darwin en el cual éste relata la manera en la que se le ocurrió la solución al dilema que hemos apuntado más arriba:

«...los pinzones de Darwin no están aislados, cada especie en su propia isla. Por término medio hay siete $\mathrm{u}$ ocho especies en cada isla del archipiélago. Además, hay un constante tráfico de pinzones visitantes. Los pájaros pueden haber divergido, pero ahora no están separados. ¿Qué sucede cuando las ramas de la vida que han empezado a bifurcarse en aislamiento se reúnen de nuevo? Darwin tenía una respuesta, y es uno de los momentos más originales de su argumentación. Puedo recordar el sitio exacto del camino, mientras viajaba en mi carruaje, donde, para alegría mía, se me ocurrió la solución, recuerda Darwin en sus memorias, y prosigue: y eso fue mucho tiempo después de llegar a Down... no fue hasta ese momento, viajando en coche, cuando Darwin sintió que realmente comprendía la ramificación del árbol de la vida. ¿Qué empujaba a las ramas a bifurcarse una y otra vez?... Súbitamente Darwin se dio cuenta de que la adaptación a aislados islotes no era toda la respuesta. Vio un modo en el que la selección natural, al actuar sobre las variedades locales... metería una cuña entre esas variedades separándolas en todo el mundo» (Weiner, 2002: p. 228).

Darwin llamó a este proceso principio de divergencia. Pero hoy en día se denomina especiación simpátrica, y es uno de los fenómenos evolutivos más significativos que podemos consignar dentro de la selección natural. Weiner dice: «Cualquier salida de esa apremiante competencia - por muy parcial que sea- le supondrá una enorme liberación, casi como si encontrara una nueva isla». Y es que de hecho no hace falta ninguna separación geográfica para que la selección natural actúe presionando a las poblaciones y las obligue a adoptar estrategias de adaptación diferentes. En la medida en que se diferencian de sus congéneres, los individuos de una misma población aumentan su propia especialización, mejorando de ese modo sus capacidades para explotar los recursos de un nicho determinado, y disminuyendo en la misma proporción la 
competencia con otros individuos de la misma especie, lo que les permitirá disfrutar de un número mayor de recursos.

En las islas de Darwin, los pinzones evolucionaron para adaptarse a la ingesta de semillas de distinto tamaño, no porque existiera una barrera geográfica que impedía su cruzamiento, sino porque esa especialización o radiación adaptativa aportaba por sí misma un claro beneficio neto.

La confirmación teórica de la idea de Darwin no llegaría hasta el siglo XX, con las investigaciones realizadas por el matrimonio Peter y Rosemary Grant en el ecosistema de las islas Galápagos. Sus estudios demostraron que la evolución biológica es algo mucho más habitual de lo que en principio podemos suponer: sucede casi a diario. Esto se debe en parte a que la especiación no es un fenómeno que venga condicionado necesariamente por la separación geográfica, sino que también se debe a una presión continua (omnipresente) que hace que aparezcan divergencias de manera espontánea dentro de la propia población, en un proceso que está íntimamente ligado con las características individuales que condicionan la existencia y el funcionamiento básico de todos los participantes. Weiner señala:

«Ahora los evolucionistas saben que el aislamiento de las especies no es simplemente una cuestión de poblaciones separadas por montañas, cañones o mares... El aislamiento de las especies consiste principalmente en las barreras invisibles que pueden eliminar una punta de población en una nueva isla o dividir una gran población en un conjunto de dispersas reservas de genes, más o menos solitarias... los pinzones de Darwin pueden cruzarse, pero hay algo que se lo impide a la mayoría. Las barreras que rodean a los pájaros son invisibles porque han sido creadas por la propia conducta de esas criaturas. No es la anatomía sin el instinto, lo que las mantiene apartadas» (Weiner, 2002: p. 257).

Lo que el matrimonio Grant descubrió es que las poblaciones de pinzones sufren un mayor grado de especialización cuando las condiciones del entorno se vuelven más adversas. En los años de sequía en los que escasean las semillas, bastan unas pocas generaciones para que se manifiesten esas diferencias en los picos de los distintos especímenes. Mientras un grupo de individuos modifica 
su conducta alimenticia y su fisonomía: adoptan instintos nuevos que les llevan a preferir las semillas más grandes y duras, y a engrosar el tamaño de su pico, otros individuos de la misma población se especializan en buscar y triturar semillas más pequeñas, por lo que sus picos no experimentan ningún engrosamiento. $Y$ esta evolución es reversible en los años de abundancia de lluvias, cuando las condiciones son más favorables, lo que pone de manifiesto la enorme plasticidad genética de los organismos, la importancia de los instintos y el comportamiento, y la eficacia de la presión selectiva y la evolución natural que actúa sobre ellos.

Cuando corren buenos tiempos, la selección natural favorece la variabilidad genética y la hibridación que da lugar a esa variabilidad. Pero en cambio, cuando llegan tiempos peores, los individuos adoptan comportamientos distintos que les llevan a reproducirse en entornos acotados y sólo con aquellos compañeros con los que guardan un mayor parecido. Weiner comenta a este respecto: «Sus linajes se unen y se separan, y de esa manera los pájaros están creándose y recreándose, una y otra vez.» (Weiner, 2002: p. 323). Resulta asombroso comprobar cómo son zarandeados estos linajes, dependiendo de la dirección de las fuerzas selectivas del entorno, casi como si se tratase de la tela de una bandera movida por el viento. Pero, sobre todo, queda demostrada la importancia que adquiere la desigualdad y la especialización a la hora de aumentar la eficacia general del sistema biológico, el cual se ve obligado a adoptar una mayor divergencia cada vez que las condiciones del medio se hacen más exigentes y reclaman un rendimiento productivo mayor. Asimismo, esta importancia se puede trasladar también al estudio de las sociedades humanas, para significar la relevancia que cobra la especialización de la mano de obra en el ámbito del mercado, la productividad, y el contexto internacional. De igual manera que los pinzones tienden a especializarse en la ingesta de un solo tipo de semillas, aunque sean mejores que los demás consumiendo varios tipos (en realidad un pinzón de pico grueso podría molturar también semillas más pequeñas sin ningún problema aparente, incluso con mejores resultados que algunos pinzones de pico más afilado), así también los países que dediquen sus recursos a la producción de un único bien, y que luego intercambien éste en el mercado internacional 
(aún a sabiendas de que pueden superar a los demás países en la fabricación de varios bienes), gozarán de mayor ventaja con respecto a aquellos que no se especializan. Y eso es, en definitiva, lo que viene a decir la ley de la ventaja comparativa que propuso David Ricardo a principios del siglo XIX.

\section{CONCLUSIONES}

Estas leyes que acabamos de ver, y otras muchas más (la ley de costes, la ley de la determinación de precios, la ley de la utilidad marginal, la ley del rendimiento decreciente), constituyen en conjunto un armazón fundamental para defender el mercado libre y las sociedades abiertas, y adquieren mayor verosimilitud cuando entendemos que resultan de aceptar otras reglas más generales, que gobiernan el funcionamiento y la homeostasis interna de todos los sistemas y de toda la naturaleza.

Todas ellas se enmarcan dentro de un campo de estudio mucho más amplio, el de las teorías de la complejidad y la teoría de sistemas, y cobran por tanto más importancia cuanto más complejo sea el objeto de estudio. Así por ejemplo, la especialización adquiere si cabe todavía más relevancia en aquellos casos en que los agentes en cuestión pueden diversificarse, relacionarse e intercambiar bienes con mayor facilidad, esto es, cuando dichos agentes conforman sociedades humanas con un elevado grado de libertad para el movimiento de bienes, capitales y personas.

En este trabajo he procurado realizar un estudio comparativo que me permitiese relacionar varias teorías en apariencia muy alejadas, unas pertenecientes al ámbito de la biología y otras inscritas en el campo más concreto de la economía. Ello me ha permitido fundamentar los teoremas y las leyes de las segundas en los preceptos y fenómenos que analizan las primeras. Sigo en eso los pasos del padre de la escuela austriaca de economía, el teórico Carl Menger, que decía lo siguiente:

«la gran difusión que la llamada concepción organicista de las formaciones sociales ha tenido en la literatura científico-social de todos los países es sin duda una prueba elocuente de que 
realmente existe una clara semejanza entre los fenómenos sociales y los organismos naturales...» (Menger, 2006: p. 207).

Como puede verse, me interesa construir una teoría económica de corte ecuménico, enriquecida con algunas nociones propias de la biología y la metodología generales, suturada con puntos de unión que favorezcan la colaboración y participación de todas las ciencias, y coronada por hitos que señalen con claridad el camino que marcan aquellos principios filosóficos en los que todas ellas se basan. No en vano, mi propósito siempre ha sido realizar un estudio metodológico completo, y utilizar éste para derivar algunas nociones válidas en todos los campos del pensamiento, que sean especialmente útiles para entender las leyes generales que rigen la economía, aquellas normas que determinan el funcionamiento del sistema más complejo de todos, que es también el sistema que más incumbe y compete al ser humano: la sociedad civil. Al fin y al cabo, es nuestra felicidad y nuestro bienestar lo que está en juego. La última implicación lógica del conocimiento siempre debería aspirar a tener un carácter deontológico y una aplicación política de corte liberal, con miras a lograr un confort general mucho mayor. Ese es el motivo de que hayamos resaltado dos propiedades importantes: la creatividad del empresario y la desigualdad de funciones. Ambas se predican directamente de la ontología más básica, y procuran a su vez muchos más beneficios al hombre (no es casualidad por tanto que tengan este abolengo). Ambas conllevan una responsabilidad y un esfuerzo individual mucho mayores, que sólo es posible encontrar en aquellos códigos morales y aquellos comportamientos éticos que están basados en el respeto a las diferencias, la pluralidad, la libertad personal, los valores meritocráticos y las destrezas competitivas que fomentan el avance, la generación de bienes, y el progreso de las sociedades. Y por supuesto, ambas están íntimamente relacionadas, como no podía ser de otra manera, con el carácter individual que detentan las personas, con los elementos más fundamentales que constituyen la realidad, y con todos aquellos atributos físicos que han estado siempre en el punto de mira del liberalismo clásico y de todas las teorías económicas que vienen posicionándose a favor del libre mercado y los derechos inalienables del individuo. 


\section{REFERENCIAS BIBLIOGRÁFICAS}

Aristóteles (2008): Metafísica, Libro VII, Madrid, Bolsillo Alianza Editorial [segunda reimpresión, 2011].

- (2012): Ética a Nicómaco, Libro I, Madrid, Bolsillo Alianza Editorial.

Bertalanffy, L. Von (1968): Teoría general de los sistemas, México, Fondo de Cultura Económica [decimoctava reimpresión, 1976]. HuerTa DE SOTO, Jesús (2010). Socialismo, cálculo económico y función empresarial, Madrid, Unión Editorial.

- (2011): «La teoría de la eficiencia dinámica», Procesos de mercado: revista europea de economía política, ISSN 1697-6797, Nº 1, 2004, pp. 11-72.

MenGer, Carl (2006). El método de las ciencias sociales, Madrid, Unión Editorial.

Nuñez de CASTro, Ignacio (2012). Enzimología, Ediciones Pirámide (grupo Anaya).

ROTHBARD, Murray N. (2004): El hombre, la economía y el estado, Madrid, Unión Editorial [2011].

WeINER, Jonathan (2002). El pico del pinzón, Barcelona, Editorial Galaxia Gutenberg.

WiLSON, Edward O. (1998): Consilience, la unidad del conocimiento, Barcelona, Editorial Galaxia Gutenberg [1999]. 
